\title{
The Relationship Between Short-Term Exposure To Air Pollution With Hospitalization and Mortality of Cardiovascular (CVD) and Respiratory Diseases in Shahrekord, Iran
}

\section{Abdolkazem Neisi}

Ahvaz Jundishapur University of Medical Sciences: Ahvaz Jondishapour University of Medical Sciences

\section{Maryam Dastoorpoor}

Ahvaz Jundishapur University of Medical Sciences: Ahvaz Jondishapour University of Medical Sciences Gholamreza Godarzi

Ahvaz Jundishapur University of Medical Sciences: Ahvaz Jondishapour University of Medical Sciences Abdolmajid Fadaei

Shahrekord University of Medical Science

Kambiz Ahmadi Angali

Ahvaz Jundishapur University of Medical Sciences: Ahvaz Jondishapour University of Medical Sciences Davood Jalili Naghan ( $\nabla$ d.jalili225@gmail.com )

Ahvaz Jundishapur University of Medical Sciences: Ahvaz Jondishapour University of Medical Sciences

\section{Research Article}

Keywords: Air pollutants, cardiovascular diseases, respiratory diseases, mortality, Shahrekord

Posted Date: September 24th, 2021

DOI: https://doi.org/10.21203/rs.3.rs-894674/v1

License: (c) (i) This work is licensed under a Creative Commons Attribution 4.0 International License.

Read Full License 


\section{Abstract}

Background and objectives: Air pollution has been widely considered as an important factor in causing heart disease, respiratory disease, and death. This study sought to determine the relationship between short-term exposure to air pollutants and hospital admissions, cardiovascular and respiratory deaths and total mortality rate in Shahrekord, Iran.

Procedure: This is a time series and ecological research. We collected data on hospital admissions and cardiovascular mortality and total mortality from 2012 to 2018.

The study used the quasi-Poisson regression combined with linear distributed lag models, adjusted for trend, seasonality, temperature, relative humidity, weekdays and holidays.

Results: Our results show a direct and significant statistical relationship between: 03 exposure in lag4 for total mortality, $\mathrm{PM}_{10}$ exposure in lag1 for total mortality and in lag 4 and lag1 for respiratory death, $\mathrm{PM}_{2.5}$ exposure for total cardiovascular admissions in lag5, respiratory mortality in lag4, total respiratory admissions in lag3, NO2 exposure to respiratory mortality in lag1, and cardiovascular mortality in lag0, increased risk of death and pathogenesis.

The results show a statistically significant inverse relationship between: NO and total admissions in lag3 and for respiratory mortality in lag1 between $\mathrm{PM}_{2.5}$ and cardiovascular mortality in lag1, NO with respiratory mortality in lag1 and cardiovascular admissions in lag3, $\mathrm{NO}_{2}$ with cardiovascular admissions in lag1 and $\mathrm{NO}_{x}$ with respiratory death in lag0, which reduces the risk of death and pathogenesis.

Conclusion: Air pollution has a significant relationship with the number of hospital admissions and mortality in Shahrekord, Iran.

\section{Introduction}

Human health is widely affected by climatic and environmental conditions. Different natural and artificial sources change the characteristics of open air (Dadbakhsh et al., 2016; Mansouri et al., 2013). Air pollution is now a public health problem. Air pollutant sources include: carbon monoxide, sulfur dioxide, sulfates, nitrogen monoxide, nitrogen dioxide, organic matter and particles (Tang et al. 2016). Overall, 3.7 million deaths, 3.1 million disabilities (DALY) are attributed to air pollution, which make it among the top 10 risk factors (Lim et al. 1990-2010). Air pollution has been widely considered as an important factor in causing heart disease, and death (Brunekreef et al. 2009). Due to its negative effects on human health, it has become a major concern for mankind (Dastoorpoor et al. 2016). Recently, two population groups (Canada and South Korea) have been subjected to cohort studies, showing air pollution as closely related to the increased prevalence of heart disease, especially atrial fibrillation (Kim et al. 2019; Shin et al. 2019). Epidemiological and clinical studies published in recent years provided compelling evidence that short-term exposure to particulate matter $\left(\mathrm{PM}_{2.5}\right)$ can lead to heart disease and cardiac accidents (Meo and Suraya 2015). The results of a meta-analysis study in China showed that with an increase of 
$\mathrm{PM}_{2.5}$ per 10 micrograms per cubic meter, mortality rate increases by $68 \%$ (Zhao et al. 2017). Studies have confirmed that patients with congestive heart failure, a history of myocardial infarction, are at greater risk on days with higher pollution rates. The likelihood of cardiovascular and respiratory deaths due to exposure to air pollutants is higher than deaths from other causes. Several studies have been conducted to investigate the impact of air pollution on mortality rate of patients with cross-sectional, cohort and time-period methodologies (Cesaroni et al., 2013; Dadbakhsh et al., 2016; Dastoorpoor et al., 2016; Dastoorpoor et al., 2019; Dastoorpoor et al., 2019; Hashemi and Khanjani, 2016;). Industrial advancements and increased number of motor vehicles have contributed to more air pollution. Therefore, conducting research in different regions around the globe could help achieve a better understanding of challenges caused by global air pollution (Saldiva et al., 1994). Unlike conventional CVD risk factors, biomarkers (such as air pollution, noise, natural environment) can be considered as potential targets for the prevention and management of pollutants (Song et al., 2016). Health problems caused by air pollution have convinced government officials and policy-makers to take action to protect and preserve the environment (Song et al., 2017). Due to dust emanating from countries neighboring Iran as well as human and environmental activities, particulate matter causes health, economic and environmental problems in the center, west and southwest, especially Chaharmahal and Bakhtiari Province (Gerivani et al., 2011). However, no study has been conducted to assess the severe effects of air pollution in Shahrekord (Western Iran). Data in this field is obtained through studies conducted by the AirQ model to estimate the effects of air pollution on heart and respiratory diseases (Dobaradaran et al., 2013; Yari et al., 2013). Information and awareness about risks associated with air pollution might pave the way for adopting better public health strategies. This is a time-series study aiming at investigating the relationship between air pollution, mortality rates and CVD.

\section{Procedure}

With an area of 70 square kilometers, Shahrekord is the center of Chaharmahal and Bakhtiari Province in Iran. The geographical coordinates of Shahrekord are $49^{\circ} 22$ / E and $32^{\circ} 20$ / N in the plains of Chaharmahal and Bakhtiari Province. According to the 2016 census, Shahrekord's population is 190,441 (statistics).

This is a time series and ecological research. We collected data related to hospital admissions, total mortality, cardiovascular and respiratory mortality from 2012 to 2018 (7 years) on a daily basis from the two main hospitals: Shahrekord and Shahrekord University of Medical Sciences.

Daily concentrations of pollutants in seven years were collected from Chaharmahal and Bakhtiari Department of Environment. Data included: ozone, carbon monoxide, nitrogen dioxide (mono and nitrogen dioxide) particles $\leq 2.5$ microns and 10 microns. Data were obtained from three monitoring stations in Jihad Square, Ostandari Square and Chaharmahal Square in Shahrekord. In these stations, air pollutants and particles $\leq 2.5$ microns and particles $\leq 10$ microns were measured separately in different ways. To measure suspended particles, we first pumped the air into the measuring devices. The device measured and recorded particle concentration hourly based on absorption intensity. The researchers 
collected relative humidity and daily temperature from the Chaharmahal and Bakhtiari Meteorological Department.

\subsection{Analysis}

This ecological study used the generalized linear models (GLM) and distributed lag models (DLM) to determine the relationship between hospital admissions and cardiovascular and respiratory mortality with daily levels of air pollutants including $\mathrm{O}_{3}, \mathrm{NO}_{2}, \mathrm{NO} \mathrm{CO}, \mathrm{NO}_{x}$ and $\mathrm{PM}_{10}$ and $\mathrm{PM}_{2 \cdot 5}$. The research used distributed lag models to evaluate the lag effect of air pollutants in the form of single lags up to seven days after exposure.

The effect of seasonality and long-term trend was adjusted through a flexible spline function of time with a degree of freedom of 7 per year (Bhaskaran et al. 2013). The effect of humidity and temperature was controlled by a natural cubic spline function with three and six degrees of freedom, respectively (Bhaskaran et al., 2013; Dastoorpoor et al., 2019; Phung et al., 2016; Ye et al., 2016).

The effect of working days, as a confounding variable in the model, was mediated, because the days of the week seem to have an effect on hospital admissions and mortality. It seems that concentration of pollutants on weekends is different from other days. Therefore, we included the effect of holidays per week in the model as a confounding variable and took its effect into account. The results of the DLM model are reported for every 10 units of increase in pollutants from $7-0$ days lag and RR rate with $95 \%$ confidence interval. All statistical analyses were performed using R software version 3.5.3 (package dlnm). Significance level was considered less than 0.05 .

\section{Results}

From 2012 to 2018, the total number of respiratory admissions was 3986 people with a daily average of 1.55 people. The highest number of daily referrals was 7 people. The total number of cardiovascular admissions was 35,928 with a daily average of 14 . Nox $x$ was the most important pollutant in Shahrekord, which varied a lot with season change. The average concentration of Nox $\mathrm{x}_{\mathrm{x}}$ was 587.51 micrograms per cubic meter during the period of our study, which exceeded the average reported by the United States Environmental Protection Agency. $\left(\mathrm{AQI}<350 \mu \mathrm{g} / \mathrm{m}^{3}\right)$. Other details on admissions, cardiovascular and respiratory mortality and air pollutants are presented in Table 1,2.

Table 1. The number of hospitalization and mortality of cardiovascular (CVD) and respiratory diseases during 2012 to 2018 


\begin{tabular}{lcccccccc}
\hline Health outcome & $\mathrm{N}$ & MEAN & SD & MIN & MAX & Q1 & MEDIAN & Q3 \\
\hline \multicolumn{1}{c}{ Total deaths } & 6081 & 2.37 & 1.413 & 0 & 21 & 2 & 2 & 3 \\
Cardiovascular deaths & 2036 & 0.79 & 0.732 & 0 & 5 & 0 & 1 & 1 \\
Respiratory deaths & 316 & 0.12 & 0.329 & 0 & 1 & 0 & 0 & 0 \\
Cardiovascular admissions & 35928 & 14 & 7.900 & 1 & 218 & 10 & 12 & 20 \\
Respiratory admissions & 3986 & 1.55 & 0.968 & 0 & 7 & 1 & 2 & 2 \\
\hline
\end{tabular}

Table2. The descriptive indices of the air pollutants and climate factors during 2012 to 2018

\begin{tabular}{ccccccccc}
\hline Pollutant & $\mathrm{N}$ & MEAN & $\mathrm{SD}$ & $\mathrm{MIN}$ & $\mathrm{MAX}$ & $\mathrm{Q} 1$ & MEDIAN & $\mathrm{Q} 3$ \\
\hline $\mathrm{O}_{3}$ & 2557 & 15.98 & 35.71 & 0.83 & 1789 & 11 & 14.93 & 18.42 \\
$\mathrm{PM}_{10}$ & 2557 & 66.23 & 44.13 & 2.42 & 502.92 & 30.54 & 60.17 & 91.47 \\
$\mathrm{PM} 2.5$ & 2557 & 49.94 & 287.48 & 0 & 353.58 & 22.43 & 36.98 & 55.71 \\
$\mathrm{NO}$ & 2557 & 77.94 & 54.20 & 0 & 1001 & 40 & 67 & 90 \\
$\mathrm{NO}_{2}$ & 2557 & 59.42 & 86.75 & 10 & 1009 & 30 & 50 & 70 \\
$\mathrm{NO}_{x}$ & 2557 & 587.51 & 22937.67 & 10 & 1101 & 90 & 120 & 160 \\
$\mathrm{CO}$ & 2557 & 0.38 & 0.31 & 0 & 0.99 & 0.1 & 0.28 & 0.61 \\
$\mathrm{O} 3$ & 2557 & 0.1 & 0.01 & 0 & 0.2 & 0 & 0.01 & 0.1 \\
Temperature & 2557 & 11.64 & 8.25 & -18.3 & 29.10 & 4.9 & 11.90 & 19 \\
Relative Humidity & 2557 & 40.7 & 18.93 & 0 & 97 & 25 & 37 & 54 \\
& & & & & & & & \\
\hline
\end{tabular}

Figure 1 to 7 presents the relationship between exposure to air pollutants (including: $\mathrm{O}_{3}, \mathrm{NO}, \mathrm{NO}_{2}, \mathrm{PM}_{10}$, $\mathrm{PM}_{2.5} \mathrm{NO}_{x}, \mathrm{CO}$ ) for every 10 micrograms per cubic meter up to a time lag of seven days after exposure, admissions and cardiovascular and respiratory mortality.

The results of the study indicate a statistically significant and direct relationship between exposure to $\mathrm{PM}_{10}$ and total deaths in lag1 $(\mathrm{RR}=1.105(95 \% \mathrm{Cl}): 1.016-1.202)$, which was associated with a $10 \%$ increased risk of total mortality. A statistically significant and direct relationship between $\mathrm{PM}_{10}$ exposure and respiratory mortality in lag4 $(\mathrm{RR}=1.894(95 \% \mathrm{Cl}): 1.281-2.799))$, and lag1 $(\mathrm{RR}=1.533(95 \% \mathrm{Cl})$ : 1.019-2.308) was associated with an increase in risk of $89 \%$ and $53 \%$, respectively (Fig. 1).

There was a statistically significant and direct relationship between exposure to $\mathrm{PM}_{2.5}$ and total cardiovascular admissions in lag5 ( $R R=1.146(95 \% \mathrm{Cl}: 1.042-1.261))$, with a $14 \%$ increased risk, respiratory mortality in lag4 ( $R R=1.842(95 \% \mathrm{Cl}$ : $1.076-3.154))$, a $84 \%$ increase in risk and respiratory admissions in lag3 (RR = 1.138 (95\% Cl: 1.003-1.292)), and a 13\% increased risk (Fig. 2).

There was a statistically significant and direct relationship between NO2 exposure and respiratory mortality in lag1 $(\mathrm{RR}=1.236(95 \% \mathrm{Cl}: 1.017-1.502))$, with a $23 \%$ increased risk as well as cardiovascular mortality in lag0 ( $R R=1.057) .95 \% \mathrm{Cl}$ : 1.008-1.109) with a $5 \%$ increase in risk (Fig. 4). 
There was a direct and significant statistical relationship between 03 exposure in lag4 and total deaths $(\mathrm{RR}=1.616$ (95\% Cl: 1.092-2.390)), with a 61\% increased risk (Fig. 6). A statistically significant and direct relationship was observed between CO exposure and respiratory mortality in lag4 (RR = 54.294 (95\% Cl: 1.136-2594.147)) (Fig. 7).

This study found a statistically significant and inverse relationship between exposure to $\mathrm{PM}_{2.5}$ and cardiovascular mortality in lag1, exposure to $\mathrm{NO}$ and respiratory mortality in lag1 and cardiovascular admissions in Lag3, $\mathrm{NO}_{2}$ exposure and cardiovascular admissions in lag1 and $\mathrm{NO}_{\mathrm{X}}$ exposure and respiratory deaths in lag0 (Fig. 2 to 5 )

\section{Discussion}

This study sought to determine the relationship between short-term exposure to air pollutants and hospital admissions and cardiovascular and respiratory mortality in Shahrekord, Iran.

We found a direct and significant statistical relationship between $\mathrm{O}_{3}$ in lag4 with total mortality $(\mathrm{RR}=$ $1.616(95 \% \mathrm{Cl}: 1.092-2.390))$ which is associated with a $61 \%$ increase in total mortality risk. A study by Jerrett $M$. in the United States found no significant association between ozone and cardiac mortality and total deaths. However, after modification of $\mathrm{PM}_{2.5}$, a slightly positive correlation was observed between ozone and mortality due to heart disease (Jerrett et al., 2009).

A study by Dockery et al. in the United Kingdom and Pope et al. in the United States reported no association between ozone and death from heart disease (Dockery et al., 1993; Pope et al., 2002).

In a study by Lipsett et al. in California, the association between ozone and death from ischemic heart disease (IHD) patients was hardly significant (hazard ratio $(H R)=1.06,95 \% \mathrm{Cl}$ : 0.99-1.06). However, when the analysis was limited to summer, a significant positive correlation was found between ozone and IHD-related death. No association was observed between ozone and cardiac deaths (HR $=1.09,95 \%$ Cl: 1.01-1.19) (Lipsett et al., 2011).

Studies in the Netherlands, Finland and Germany on the effects of air pollution on blood pressure have found a significant negative correlation for ozone in multicenter studies (Ibald-Mulli et al., 2004).

The results of this study showed a statistically significant and direct relationship between exposure to $\mathrm{PM}_{10}$ and total deaths in lag1 ( $\mathrm{RR}=1.105(95 \% \mathrm{Cl}$ : 1.016-1.202)), which was associated with a $10 \%$ increased risk of total death. There was also a statistically significant and direct relationship between $\mathrm{PM}_{10}$ exposure and respiratory mortality in lag4 $(\mathrm{RR}=1.894(95 \% \mathrm{Cl}: 1.281-2.799))$, and lag1 $(\mathrm{RR}=1.533$ (95\% Cl: 1.019-2.308)), which was associated with $89 \%$ and $53 \%$ increases in risk, respectively.

A study in Ahvaz showed that the toxicity and risk of $\mathrm{PM}_{10}$ for the lung is more severe on dusty days than on other days due to more inhalation of pollutants (Naimabadi et al. 2016). 
The EPA has shown that $\mathrm{PM}_{10}$ is exposed to oxidative stress and increased inflammatory markers in individuals (US Environmental Protection Agency. 40 CFR Part 50. National Ambient Air Quality Standards for particulate matter. Final rule. Fed Regist 2006;71:61144-233).

Analysis of the results of several studies has suggested that $\mathrm{PM}_{10}$ is effective in admitting respiratory patients to the hospital. For example, a 2001 study by Atkinson et al. in eight European cities found that for every 10 micrograms of $\mathrm{PM}_{10}$ increase, the risk of respiratory disease increases to 0.9 percent (Atkinson et al., 2001).

The results of this study showed a statistically significant and direct relationship between exposure to $\mathrm{PM}_{2.5}$ and cardiovascular admissions in lag5 ( $\left.\mathrm{RR}=1.146(95 \% \mathrm{Cl}: 1.042-1.261)\right)$, respiratory mortality in lag4 ( $R R=1.842(95 \% \mathrm{Cl}: 1.076-3.154)$ ) and respiratory admissions in lag3 ( $R R=1.138$ (95\% Cl: $1.003-$ 1.292)).

A study by Kloog et al. (2014) on three million CVD admissions in the United States estimated that for every 10 micrograms per cubic meter of $\mathrm{PM}_{2.5}$, the delay increased from $0-1 \mathrm{PM}_{2.5}, 1.04(0.56 \otimes \nabla 1.51 \rrbracket)$ $0.7 \bigotimes(0.44 \rrbracket, 0.96 \rrbracket)$ were observed in rural and urban areas, respectively (Kloog et al., 2014).

A study by Qing Tian et al. in Shanghai, China, found that for every 10 micrograms per cubic meter of $\mathrm{PM}_{2.5}$, there would be a 1.26 percent increase in cardiovascular disease (CVD) mortality $(1.26 \%)(95 \% \mathrm{Cl}$ : $0.40 \%, 2.12 \%$ ) which is higher compared to other studies (between $0.63 \%$ and $0.80 \%$ ) (Achilleos et al., 2017; Lu et al., 2015).

A multicenter meta-analysis study in Shanghai, China, East Asia suggested that for every 10 micrograms per cubic meter of $\mathrm{PM}_{2.5}$ increased by $0.96 \%, 0.96 \%$ (95\% Cl: $\left.0.46 \%, 1.46 \%\right)$, there was an increase in mortality from heart disease, which is relatively similar to this study (Lee et al., 2015).

A study by $\mathrm{Xu}$ et al. showed that increasing every 10 micrograms per cubic meter of $\mathrm{PM}_{2.5}$ concentration is positively associated with a $0.56 \%$ increase in CHD uptake in lag0-1 (95\% Cl: $0.16-0.95 \%$ ), and an increase of $0.81 \%(\mathrm{HRD})$ to $1.57 \%$ lag0-1 (95\% Cl: 0.05 - and $1.21 \%$ increase in (HF) (95\% Cl: 0.272.15\%) (Xu et al., 2016).

A significant relationship was found between daily mortality with an increase in $\mathrm{PM}_{2.5}$ and $\mathrm{PM}_{10}$ in one day and a cumulative delay of 6 days in Taiyuan, which is consistent with previous studies (Liang et al., 2018).

Several studies have shown a positive statistical association between CVD-related mortality and infection with $\mathrm{PM}_{2.5}$ (Ma et al., 2017; Su et al., 2016).

A recent study on 248 cities in China found that a $10 \mu \mathrm{g} / \mathrm{m} 3$ increase in $\mathrm{PM}_{2.5}$ was significantly associated with a $0.26 \%$ increase in hospital admission for transient ischemic attack (TIA) (Gu et al., 2020). 
A statistically significant relationship was found between $\mathrm{NO}_{2}$ exposure and death from loss of respiration in lag1 $(\mathrm{RR}=1.236(95 \% \mathrm{Cl}: 1.017-1.502)$ ), with a $23 \%$ increased risk as well as cardiovascular mortality in lag0 ( $R R=1.057(95 \% \mathrm{Cl}$ : $1.008-1.109))$, with a $5 \%$ increase in risk.

Multivariate regulated analysis used in a study on relationship between air pollution and mortality in French showed that relative risk of deaths from heart disease is $1.27 \mathrm{NO}_{2}$ micrograms per cubic meter (95\% Cl: 1.04- 1.56), which is statistically significant (Filleul et al., 2005).

Dadbakhsh et al. in Shiraz found that $\mathrm{NO}$ and $\mathrm{NO}_{\mathrm{X}}$ had a significant and direct relationship with total deaths from heart disease and female deaths in the same month and the following month (Dadbakhsh et al., 2016).

The strengths of this study were: Firstly, all data related to diseases and mortality were collected from government and trusted organizations in Chaharmahal and Bakhtiari Province (Shahrekord), making it a relatively large sample size. Secondly, a 7-year period and the large amount of data allowed us to examine interactions with a high level of validity and reliability. Thirdly, inclusion of three air pollution monitoring sites provided us the basis for better demonstration of the effects of air pollution compared to other studies.

Another strength of our study is taking advantage of approaches and methodology used in studies conducted in Europe, examining the potential role of dust as a mediator of the relationship between exposure to particles and mortality.

Our research has some limitations. Similar to other studies, the effects and interplay between air pollutants and health (mortality and hospital admission) requires further research. The effect might vary for each region.

4.1. Conclusion Air pollution is significantly associated with hospital admissions and mortality in Shahrekord, Iran. Effective interventions and environmental policies need to be implemented and adopted to mitigate air pollution and minimize exposure to pollutants.

\section{Declarations}

\section{Declarations:}

QThe authors declare that they have no known competing financial interests or personal relationships that could have appeared to influence the work reported in this paper.

\section{Credit Author Statement}

Author Contributions:

Collecting data: Davood Jalili Naghan and Abdolkazem NaeisiT Maryam Dastoorpoor 
Study concept and design: Davood Jalili Naghan, Maryam Dastoorpoor and Abdolkazem Naeisi

Analysis and interpretation of data: Davood Jalili Naghan and Maryam Dastoorpoor and Abdolkazem Naeisi, Gholamreza Godarzi

Drafting of the manuscript: Davood Jalili Naghan , Maryam Dastoorpoor, Abdolkazem Naeisi, Gholamreza Godarzi

Statistical analysis: Davood Jalili Naghan, Maryam Dastoorpoor, Abdolmajid Fadaei and Kambiz Ahmadi Angale

Translate: Davood Jalili Naghan, Abdolkazem Naeisi, Maryam Dastoorpoor, Abdolmajid Fadaei and Kambiz Ahmadi Angale and Gholamreza Godarzi

\section{CONFLICT OF INTEREST DECLARATION AND AUTHOR AGREEMENT}

We have no conflict of interest to declare.

This statement is to certify that all Authors have seen and approved the manuscript being submitted. We warrant that the article is the Authors' original work. We warrant that the article has not received prior publication and is not under consideration for publication elsewhere. On behalf of all Co-Authors, the corresponding Author shall bear full responsibility for the submission.

This research has not been submitted for publication nor has it been published in whole or in part elsewhere. We attest to the fact that all Authors listed on the title page have contributed significantly to the work, have read the manuscript, attest to the validity and legitimacy of the data and its interpretation, and agree to its submission to the Journal of Environmental Research.

All authors agree that author list is correct in its content and order and that no modification to the author list can be made without the formal approval of the Editor-in-Chief, and all authors accept that the Editorin-Chief's decisions over acceptance or rejection or in the event of any breach of the Principles of Ethical Publishing in the Journal of Environmental Science and Pollution Research being discovered of retraction are final.

No additional authors will be added post submission, unless editors receive agreement from all authors and detailed information is supplied as to why the author list should be amended.

Ethical Approval: Not applicable

Consent to Participate: Not applicable

Consent to Publish: All authors are satisfied that the article is published in the Journal of Environmental Science and Pollution Research

Funding: Not applicable 
Availability of data and materials: All data is available in the listed organizations

\section{References}

1. Achilleos S, Kioumourtzoglou MA, Wu CD, Schwartz JD, Koutrakis P, Papatheodorou SI (2017) Acute effects of fine particulate matter constituents on mortality: A systematic review and meta-regression analysis. Environ Int 109:89-100. [CrossRef]

2. Atkinson RW, Ross Anderson H, Sunyer J, Ayres J, Baccini M, Vonk JM et al (2001) Acute effects of particulate air pollution on respiratory admissions: results from APHEA 2 project. Am J Respir Crit Care Med 164(10):1860-1866

3. Bhaskaran K, Gasparrini A, Hajat S, Smeeth L, Armstrong B (2013) Timeseries regression studies in environmental epidemiology. Int J Epidemiol 42(4):1187-1195. doi:10.1093/ije/dyt092

4. Brunekreef B, Beelen R, Hoek G, Schouten L, Bausch-Goldbohm S, Fischer P, Armstrong B, Hughes E, Jerrett $M$, van den Brandt $P$ (2009) Effects of long-term exposure to traffic-related air pollution on respiratory and cardiovascular mortality in the Netherlands: The NLCS-AIR study. Res Rep Health Eff Inst 139:5-71

5. Cesaroni G, Badaloni C, Gariazzo C, Stafoggia M, Sozzi R, Davoli M et al. Long-term exposure to urban air pollution and mortality in a cohort of more than a million adults in Rome. Environ Health Perspect. 2013;121(3):324-328, https:// doi.org/10.1289/ehp.1205862

6. Dadbakhsh M, Khanjani N, Bahrampour A. Death from cardiovascular diseases and air pollution in Shiraz, Iran (March 2006-March 2012). J Epidemiol Prev Med. 2016;2(1):114

https://doi.org/10.19104/jepm.2016.114.Dastoorpoor M, Idani E, Khanjani N, Goudarzi G, Bahrampour A. Relationship between air pollution, weather, traffic, and traffic-related mortality. Trauma Mon 2016; 21: e37585. doi: 10.5812/traumamon.37585

7. Dastoorpoor M, Masoumi K, Vahedian M et al, Associations of short-term exposure to air pollution with respiratory hospital admissions in Ahvaz Iran. Process safty and environmental protection. 2019.123:150-160

8. Dastoorpoor M, Sekhavatpour Z, Masoumi K et al (2019) Air pollution and hospitaj admissions for the cardiovascular disaes in the Ahvaz iran. Science of The total Environment 652:1318-1330

9. Dobaradaran S, Geravandi S, Goudarzi G, Idani E, Salmanzadeh S, Soltani F et al (2016) Determination of cardiovascular and respiratory diseases caused by $\mathrm{PM}_{10}$ exposure in Bushehr, 2013. J Mazandaran Univ Med Sci 26(139):42-52

10. Dockery DW, Pope CA, Xu X, Spengler JD, Ware JH, Fay ME et al (1993) An association between air pollution and mortality in 6 US cities. New Engl J Med 329(24):1753-1759.

https://doi.org/10.1056/NEJM199312093292401

11. Filleul L, Rondeau V, Vandentorren S, Le Moual N, Cantagrel A, Annesi-Maesano I et al. Twenty five year mortality and air pollution: Results from the French PAARC survey. Occup Environ Med. 2005;62(7):453-460, https://doi. org/10.1136/oem.2004.014746 
12. Gerivani H, Lashkaripour GR, Ghafoori M, Jalali N (2011) The source of dust storm in Iran: a case study based on geological information and rainfall data. Carpathian Journal of Earth Environmental Sciences 6(1):297-308

13. Gu J, Shi Y, Chen N, Wang H, Chen T (2020) Ambient fine particulate matter and hospital admissions for ischemic and hemorrhagic strokes and transient ischemic attack in 248 Chinese cities

14. Hashemi $\mathrm{Y}$, Khanjani N (2016) Air pollution and cardiovascular hospital admissions in Kerman, Iran. J Heart Cardiol 2(2):1-6. https://doi.org/10.15436/2378-6914.16.018

15. Ibald-Mulli A, Timonen KL, Peters A, Heinrich J, Wolke G, Lanki T et al. Effects of particulate air pollution on blood pressure and heart rate in subjects with cardiovascular disease: A multicenter approach. Environ Health Perspect. 2004 Mar;112(3):369-377, https://doi.org/10.1289/ ehp.6523

16. Jerrett M, Burnett RT, Pope CA III, Ito K, Thurston G, Krewski D et al. Long-term ozone exposure and mortality. New Engl J Med. 2009;360(11):1085-1095, https://doi.org/ 10.1056/NEJMoa0803894

17. Kim IS, Yang PS, Lee J, Yu HT, Kim TH, Uhm JS, Pak HN, Lee MH,Joung B. Long-term exposure of fine particulate matter air pollution and incident atrial fibrillation in the general population: a nationwide cohort study (2019) Int J Cardiol 283:178-183

18. Kloog I, Nordio F, Zanobetti A, Coull BA, Koutrakis P, Schwartz JD (2014) Short term effects of particle exposure on hospital admissions in the Mid-Atlantic states: a population estimate. PloS One 9:e88578

19. Lee H, Honda Y, Hashizume M, Guo YL, Wu CF, Kan H, Jung K, Lim YH, Yi S, Kim H (2015) Short-term exposure to fine and coarse particles and mortality: A multicity time-series study in East Asia. Environ Pollut 207:43-51. [CrossRef]

20. Liang F, Xiao Q, Gu D, Xu M, Tian L, Guo Q, Wu Z, Pan X, Liu Y (2018) Satellite-based short- and longterm exposure to $\mathrm{PM}_{2.5}$ and adult mortality in urban Beijing, China. Environ Pollut 242, 492-499. https://doi.org/10.1016/j. envpol.2018.06.097

21. Lim SS, Vos T, Flaxman AD, Danaei G, Shibuya K, Adair-Rohani H et al (2012) A comparative risk assessment of burden of disease and injury attributable to 67 risk factors and risk factor clusters in 21 regions, 1990-2010: a systematic analysis for the global burden of disease study 2010. Lancet 380:2224-2260

22. Lipsett MJ, Ostro BD, Reynolds P, Goldberg D, Hertz A, Jerrett M et al (2011) Long-term exposure to air pollution and cardiorespiratory disease in the California teachers study cohort. Am J Respir Crit Care Med 184(7):828-835. https://doi.org/10.1164/rccm.201012-20820C

23. Lu F, Xu D, Cheng Y, Dong S, Guo C, Jiang X, Zheng X (2015) Systematic review and meta-analysis of the adverse health e_ects of ambient $\mathrm{PM}_{2.5}$ and $\mathrm{PM}_{10}$ pollution in the Chinese population. Environ Res 136:196-204. [CrossRef]

24. Mansouri F, Khanjani N, Pourmousa R. Forecasting ambient air pollutants by time series models in Kerman, Iran. J School Public Health Inst Public Health Res. 2013;11(2):75-86. Mao H, 2017. Air pollution in China: status and spatiotemporal variations. Environ. Pollut. 227, 334-347 
25. Ma Y, Zhao Y, Yang S, Zhou J, Xin J, Wang S, Yang D (2017) Short-term effects of ambient air pollution on emergency room admissions due to cardiovascular causes in Beijing, China. Environ Pollut 230:974-980

26. Meo SA, Suraya F (2015) Effect of environmental air pollution on cardiovascular diseases. Eur Rev Med Pharmacol Sci 19:4890-4897. JPubMed]

27. Naimabadi A, Ghadiri A, Idani E, Babaei AA, Alavi N, Shirmardi M, Khodadadi A, Marzouni MB, Ankali $\mathrm{KA}$, Rouhizadeh A, Goudarzi G (2016) Chemical composition of $\mathrm{PM}_{10}$ and its in vitro toxicological impacts on lung cells during the Middle Eastern Dust (MED) storms in Ahvaz. Iran Environ Pollut 211:316-324

28. Phung D, Hien TT, Linh HN et al. Air pollution and risk of respiratory and cardiovascular hospitalizations in the most populous city in Vietnam. Sci Total Environ. 2016;557:322-330. doi:10.1016/j. scitotenv.2016.03.070

29. Pope CA III, Burnett RT, Thun MJ, Calle EE, Krewski D, Ito K et al (2002) Lung cancer, cardiopulmonary mortality, and long-term exposure to fine particulate air pollution. JAMA 287(9):1132-1141. https://doi.org/10.1001/jama.287.9.1132

30. Saldiva PH, Lichtenfels A, Paiva P, Barone I, Martins M, Massad E et al (1994) Association between air pollution and mortality due to respiratory diseases in children in São Paulo, Brazil: A preliminary report. Environ Res 65(2):218-225. https://doi.org/10.1006/enrs.1994.1033

31. Shin S, Burnett RT, Kwong JC, Hystad P, van Donkelaar A, Brook JR, Goldberg MS, Tu K, Copes R, Martin RV et al (2019) Ambient air pollution and the risk of atrial fibrillation and stroke: a populationbased cohort study. Environ Health Perspect 127:87009

32. Song X, Liu Y, Hu Y, Zhao X, Tian J, Ding G, Wang S (2016) Short-term exposure to air pollution and cardiac arrhythmia: a meta-analysis and systematic review. Int J Environ Res Public Health 13:642654

33. Su C, Breitner S, Schneider A, Liu L, Franck U, Peters A, Pan X (2016) Short-term effects of fine particulate air pollution on cardiovascular hospital emergency room visits: a time-series study in Beijing, China. Int Arch Occup Environ Health 89(4):641-657

34. Tang L, Wang Q-Y, Cheng Z-P, Hu B, Liu J-D, Hu Y (2016) Air pollution and venous thrombosis: a metaanalysis. Sci Rep 6:32794

35. US Environmental Protection Agency (2006) 40 CFR Part 50. National Ambient Air Quality Standards for particulate matter. Final rule. Fed Regist 71:61144-61233.

https://www.federalregister.gov/documents/2006/10/17/06-8477/national-ambient-airqualitystandards- for-particulate-matter

36. Xu Q, Li X, Wang S, Wang C, Huang F, Gao Q, Wu L, Tao L, Guo J, Wang W,et al (2016) Fine particulate air pollution and hospital emergency room visits for respiratory disease in urban areas in Beijing, China, in 2013. PLoS One 11(4):e0153099

37. Yari AR, Goudarzi G, Geravandi S, Dobaradaran S, Yousefi F, Idani E et al. Study of ground-level ozone and its health risk assessment in residents in Ahvaz City, Iran during 2013. Toxin Rev. 2016;35(3- 
4):201-206, https://doi.org/10.1080/1556 9543.2016.1225769

38. Ye X, Peng L, Kan H et al (2016) Acute effects of particulate air pollutionon the incidence of coronary heart disease in Shanghai, China. PLoS One 11(3):e0151119. doi:10.1371/journal.pone.0151119

39. Zhao L, Liang HR, Chen FY, Chen Z, Guan WJ, Li JH (2017) Association between air pollution and cardiovascular mortality in China: A systematic review and meta-analysis. Oncotarget 8:6643866448.]CrossRef]

\section{Figures}

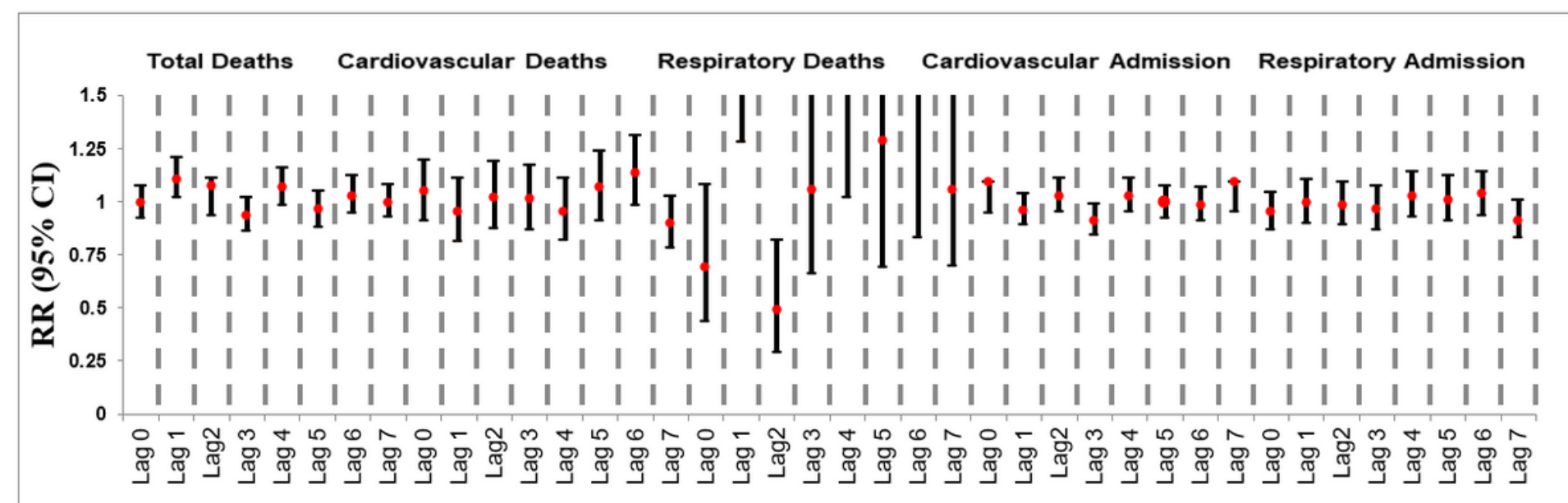

Lag Day

\section{Figure 1}

RRs ( $95 \% \mathrm{Cls}$ ) of hospitalization and mortality of cardiovascular (CVD) and respiratory diseases and total mortality with an increase of $10 \mu \mathrm{g} / \mathrm{m} 3$ in PM10 according to single lag, adjusted unconstrained and constrained DLM models

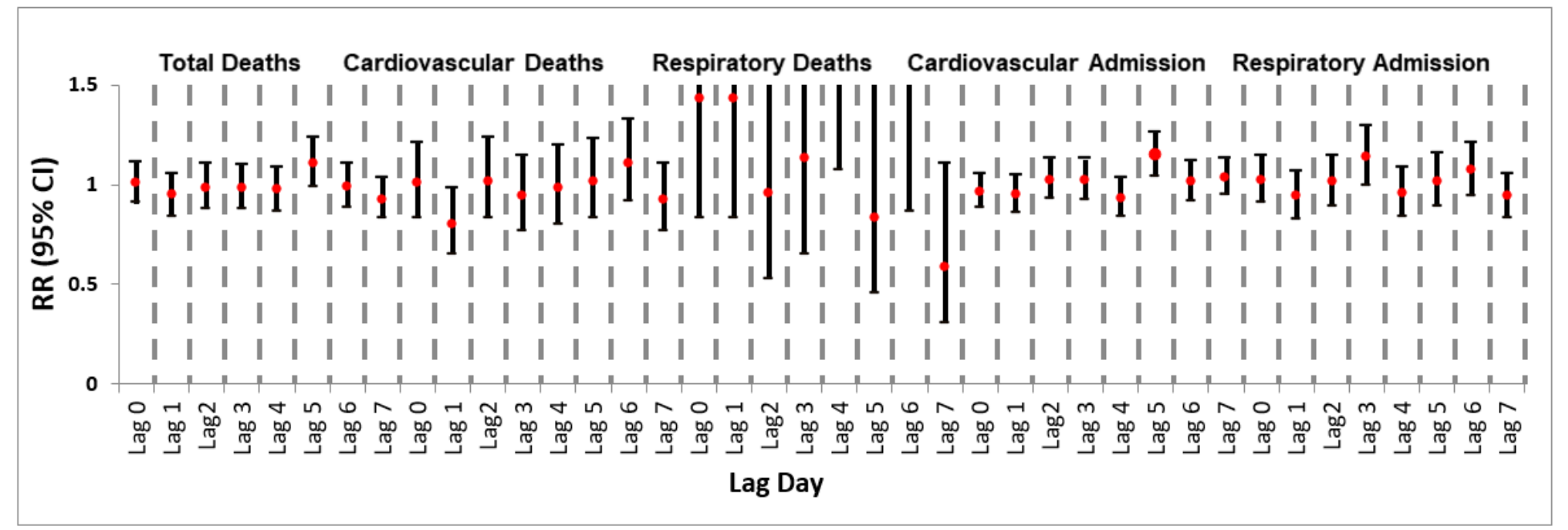

Figure 2 
RRs (95\% Cls) of hospitalization and mortality of cardiovascular (CVD) and respiratory diseases and total mortality with an increase of $10 \mu \mathrm{g} / \mathrm{m} 3$ in PM2.5 according to single lag, adjusted unconstrained and constrained DLM models

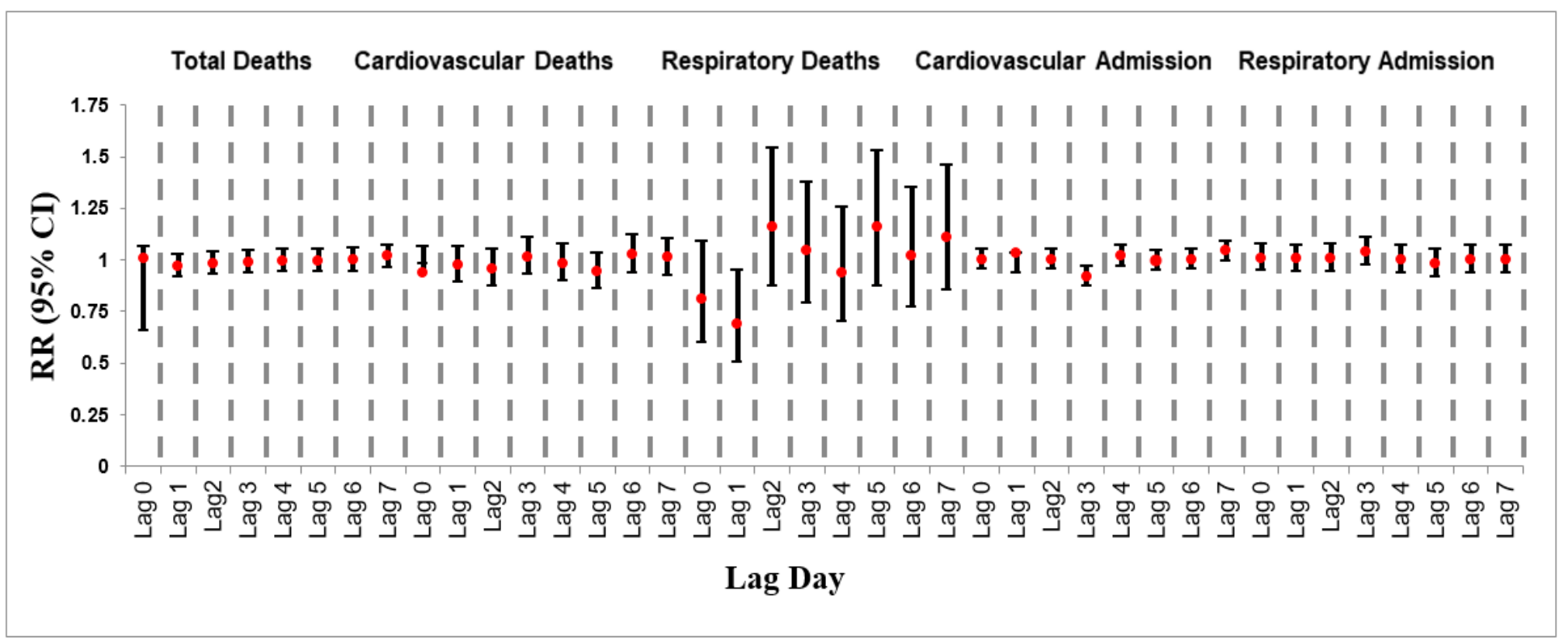

\section{Figure 3}

RRs (95\% Cls) of hospitalization and mortality of cardiovascular (CVD) and respiratory diseases and total mortality with an increase of $10 \mu \mathrm{g} / \mathrm{m} 3$ in NO according to single lag, adjusted unconstrained and constrained DLM models

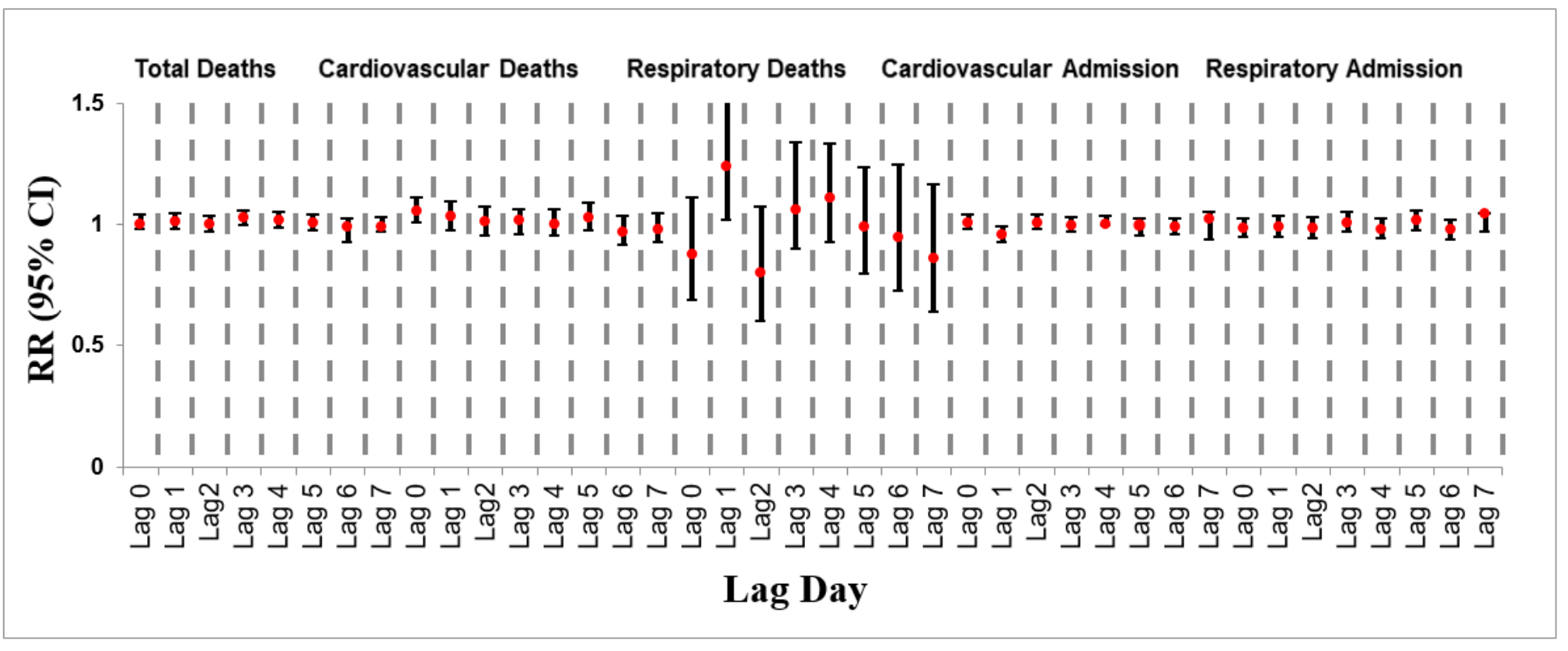

Figure 4

RRs ( $95 \% \mathrm{Cls}$ ) of hospitalization and mortality of cardiovascular (CVD) and respiratory diseases and total mortality with an increase of $10 \mu \mathrm{g} / \mathrm{m} 3$ in NO2 according to single lag, adjusted unconstrained and constrained DLM models 


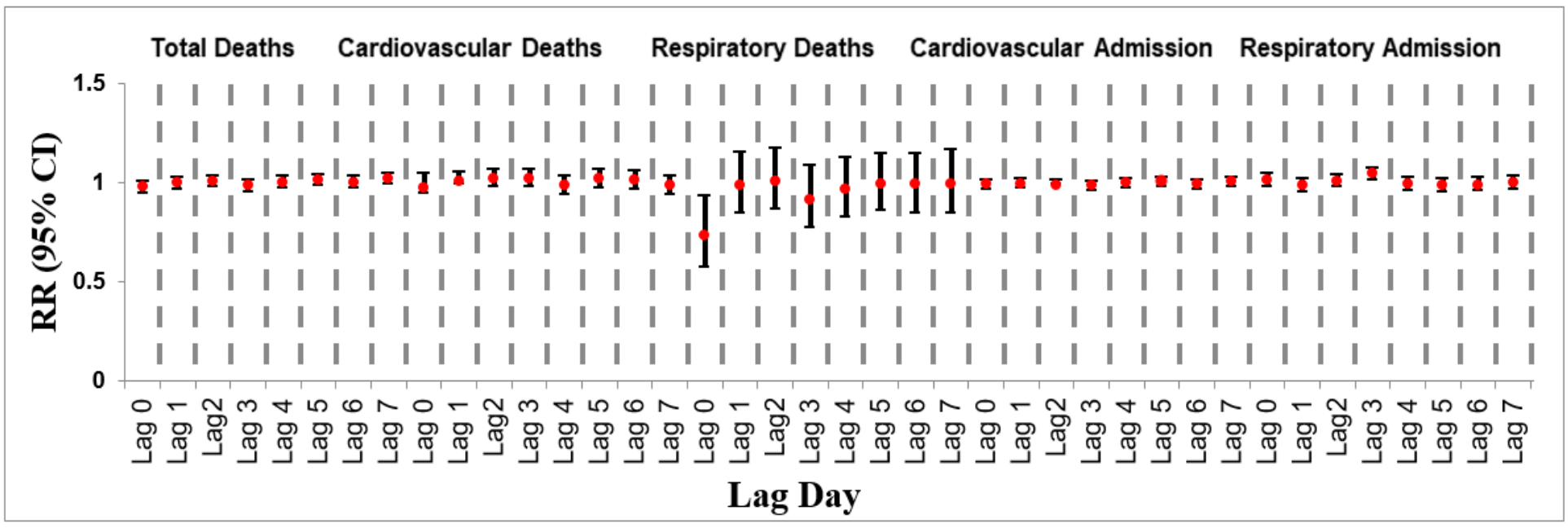

Figure 5

RRs ( $95 \%$ Cls) of hospitalization and mortality of cardiovascular (CVD) and respiratory diseases and total mortality with an increase of $10 \mu \mathrm{g} / \mathrm{m} 3$ in NOX according to single lag, adjusted unconstrained and constrained DLM models

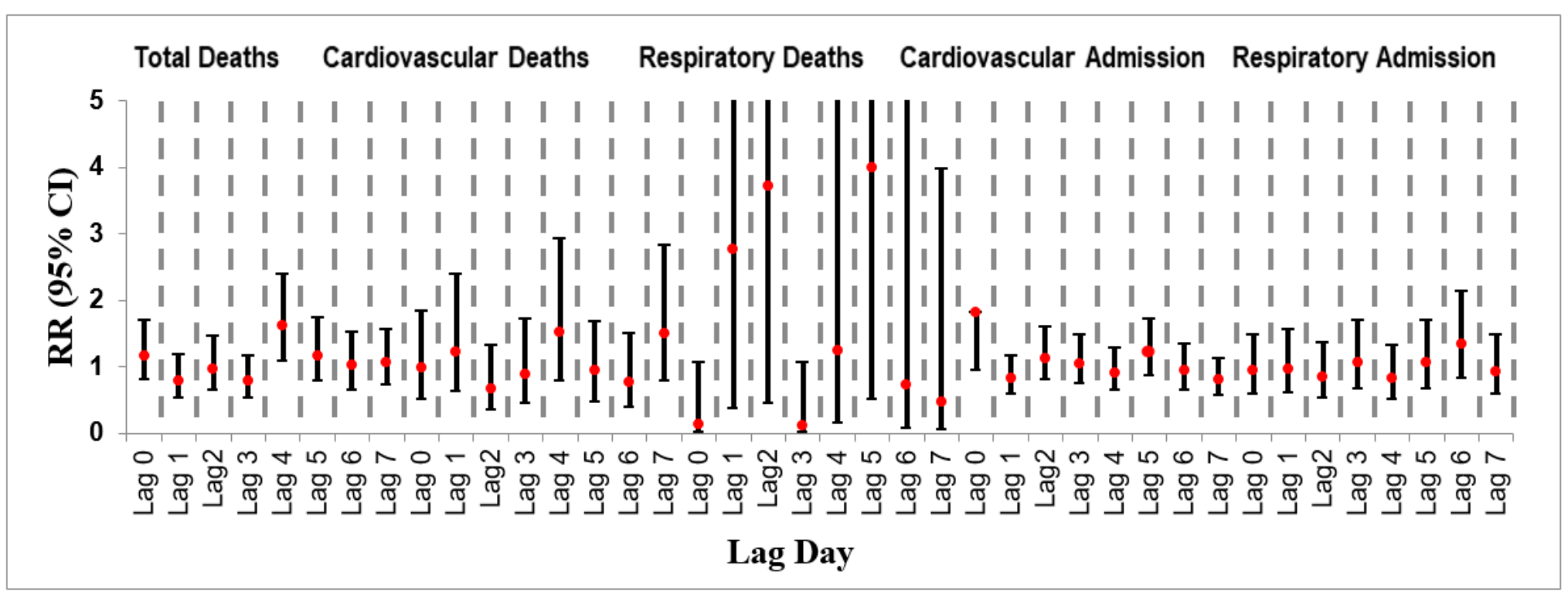

Figure 6

RRs (95\% Cls) of hospitalization and mortality of cardiovascular (CVD) and respiratory diseases and total mortality with an increase of $10 \mu \mathrm{g} / \mathrm{m} 3$ in 03 according to single lag, adjusted unconstrained and constrained DLM models 


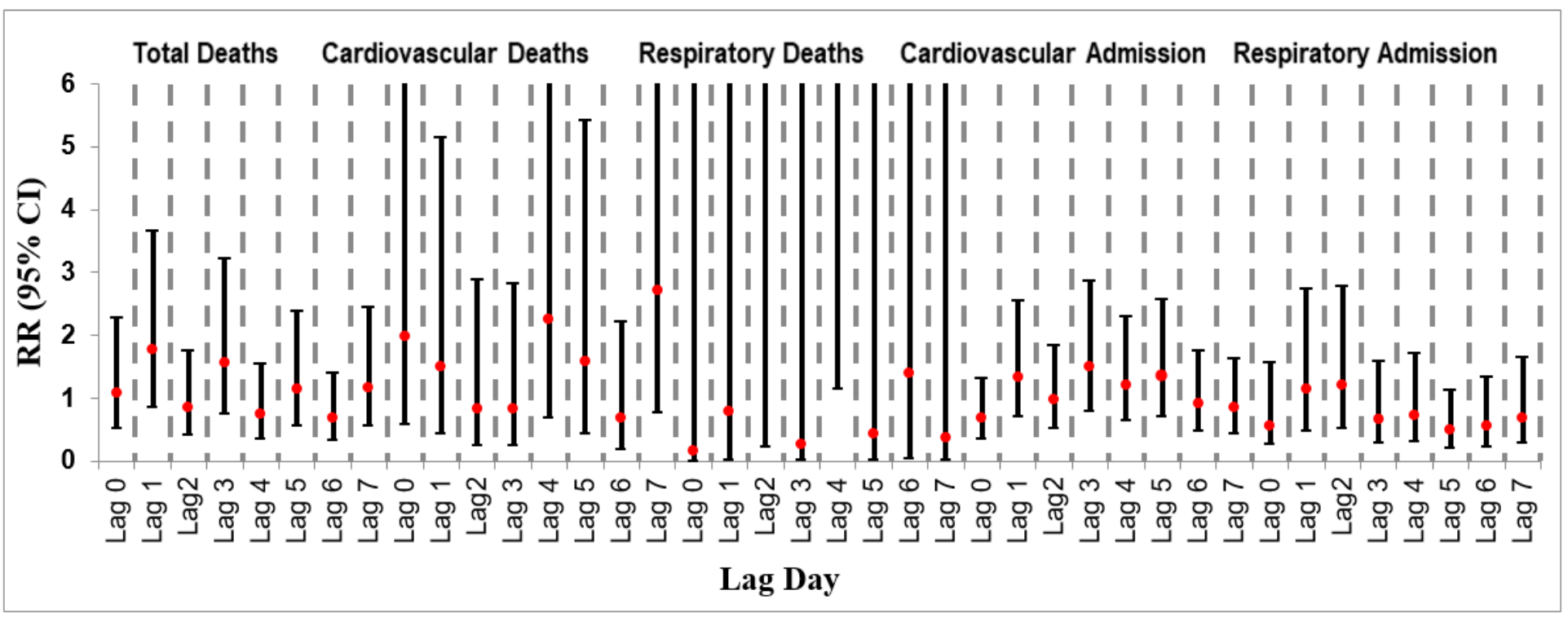

Figure 7

RRs (95\% Cls) of hospitalization and mortality of cardiovascular (CVD) and respiratory diseases and total mortality with an increase of $10 \mu \mathrm{g} / \mathrm{m} 3$ in $\mathrm{CO}$ according to single lag, adjusted unconstrained and constrained DLM models 